\title{
SLiCING ANd Dicing CoMmunity Engaged LEARNING IN ENGINEERING EDUCATION
}

\author{
Lauren Jatana, Robert Brennan, Marjan Eggermont \\ University of Calgary \\ lvathje@ucalgary.ca, rbrennan@ucalgary.ca, meggermo@ucalgary.ca
}

\begin{abstract}
Community engaged learning (community engagement or service learning) is known to be an effective pedagogy to develop social responsibility and many engineering graduate attributes (outcomes). However, as community engaged learning is a pedagogy still establishing itself in engineering education the scope and boundaries are still being defined.

Studies that report on implementation of community engaged learning have sometimes been characterized as anecdotal and isolated. Before we increase focus on work that measures impact and suggests strategic use of community engaged learning pedagogy - we must begin to tie down the scope, terminology and types of community engaged learning to ensure that a cohesive body of knowledge is formed.

This paper is largely a literature review of community engaged learning and how categorizing has been approached. The purpose of this paper is to call attention for the need of more systemized reporting of community engaged learning. In our review, we find that there are two general strategies for distinguishing one type of community engaged learning type from another. In a collaborative spirit, we use the merits of both approaches to categorizing community engaged learning to conduct a thought-experiment towards finding a middle ground for conventions when reporting community engaged learning experiences.
\end{abstract}

Keywords: Community Engaged Learning, Service Learning, Social Responsibility, Terminology, Types

\section{INTRODUCTION}

An engineer's role is constantly adapting to meet the current needs of society. Before it was to find a way to 'do it', then it transformed into find a way to 'do it cost effectively', and now the paradigm shift of an engineer's role is to find a way to 'do it, cost effectively yet responsibly for the world'. As such, a sense of professional social responsibility is a key quality for the 21 st century engineer. Engineers will play a role in solving the 'grand' challenges of society as outlined by the National Academy of Engineering, which are socially oriented and will revolve around global access to clean drinking water, making solar energy economical, engineering better medicines and so on [1]. Engineers play a critical role in solving these grand challenges because of their distinct professional skillset. The traditional skill set is well represented in traditional curriculum, but the current mission is to embed this social dimensions into engineering education [2] to ensure engineers will be ready to manage these grand challenges. Accreditation boards in America and Canada (acronyms are $\mathrm{ABET}, \mathrm{CEAB}$ respectively) and other published work have illustrated this imperative in the accreditation criteria for education [3,4]. Additionally such an imperative for socially oriented engineering is seen in various other literature $[2,5]$. In response, there has also been an emergence of global and humanitarian engineering programs $[6,7]$

This term, social responsibility (SR), can be described as a sense of obligation to society in a personal and/or professional capacity. Social responsibility is related to 3 graduate attributes (which is the Canadian Equivalent of graduate outcomes) including professionalism, understanding impact on society and the environment and ethics and equity (and similar equivalent American outcomes, c, f, h). A sense of social responsibility is developed over ones lifetime and is rooted in professional values and identity. Recently, Bielefeldt and Canney [8][10] have also contributed much effort on developing a survey tool and framework on how to measure and development social responsibility.

Social responsibility development can be developed through Community-Engaged Learning (CEL) (also known as service Learning) [8], [11], where community engaged learning is a pedagogy that involves projects that involve a reciprocal relationship between meeting learning objectives and community needs and hinges on the process of reflection [12], [13]. Community engaged learning activities have shown to encourage development of cognitive and affective measures, values [14] and professional skills. 
Community-Engaged Learning has been deliberated in a myriad of papers and books to try to tie down the proper terminology and ways of typifying and scoping different kinds of service learning or community engagement over the last couple decades. Vanasupa and Schlemer [15] point out that different terminologies such as 'service learning' and 'community engaged learning' are regularly used interchangeably, where Carberry's [16] dissertation work branches this term 'service learning' under a larger term called 'learning through service (LTS)', and Cooper's [8] investigation of social responsibility development separates community engaged learning into just three types: 'Traditional Community Engagement', 'Cocurricular' and 'Curricular Service Learning'. Also, depending on geographic factors, universities may have "Centers for Community Engaged Learning" or "Center for Service Learning and Civic Engagement", or "Community Engagement" and so on. One can quickly see why the terminology alone erodes the quest for research alignment and ability to make comparisons of studies with this pedagogy.

In recent years there have been various community engaged learning activities successfully worked into an engineering program design for the benefit of reaching graduate attributes and social responsibility development. And we now have all the tools to move forward with measuring social responsibility for strategic development in engineering programs such as pedagogies, framework and survey measurement tool. Engineering education research has already begun to explore how different types of CEL can be used in engineering programs to optimize/impact different types of social responsibility development. [11], [17], [18]

Given the momentum in CEL use in engineering, and the foundational work that has been done - the time is now to increase rigour in finding alignment in how we define details of community engaged learning. Up to now, there are critiques on the reporting on the success of CEL projects and programs as being "undifferentiated pedagogy with presumed general characteristics" [15]. To progress in strategic adoption of CEL grounded in valuable research based evidence, we need to start with a unified language and classification structure.

While we are waiting for literature to tie down the exact term and definition - generally community engaged learning is a pedagogy that uses a reciprocal relationship to meet educational objectives in a community context. It has elements of both educational goals, and of meeting actual needs of the community. Community engaged learning is enticing in that it is an effective education approach to reach the affective domain such as value development, can emphasize the social context of engineering, touches many professional skills, and it provides project and experience based learning opportunities. Community engagement is shaping up as a rapidly developing technique infiltrating courses and other educational contexts.

The purpose of this paper is to call attention for the need of more systemized reporting of community engaged learning as pedagogy in engineering. This paper begins with a literature review of community engaged learning and how categorizing has been approached in the 90's until now. We find that there are two general strategies for distinguishing one type of community engaged learning from another - where one type is simple and theoretical, and the other is elaborate and detailed. In a collaborative spirit, we use the merits of both approaches to categorizing community engaged learning to conduct a thought-experiment towards finding a middle ground for conventions when reporting community engaged learning experiences.

The goal of the paper is not to impose a new model or naming convention, but instead to evoke questions on why and how we intend to distinguish and compare one technique to another for research purposes, and support implementation and understanding the pedagogy of community engaged learning for engineering educators.

\section{BACKGROUND AND LITERATURE REVIEW}

Some further background on Community engaged learning is provided with regard to examples of implementation in engineering, and educational benefits that are related to community engaged learning. Then a review is conducted on how categorizing community engaged learning has been approached in the past.

\subsection{Not all community engaged learning is created equal}

Community Engaged Learning (CEL) or service learning is gaining momentum in engineering and it is manifested through an entire spectrum in engineering. There is an obvious movement towards adapting CELs in engineering education, and moreover there is obviously a whole spectrum of approaches to incorporate this pedagogical tool.

There are many programs and examples of CEL in engineering. CELs can look like co-curricular experiences and groups, such as EWB (Engineers Without Borders), Project 90 (engineering for the other $90 \%$ ), Brigades, Peace Corps, Habitat for Humanity, Homes of Hope, Alternative Spring Break and so on. These are often voluntary, often co-curricular, local or global, may be engineering-focused or not, forms of CELs that can impact varying learning objectives over the course of 2hours of participation up to half-a-decade or more. $[11,19,15]$

In engineering specifically, there are also a whole variety of design based and capstone projects rooted in the social dimension of engineering - with either 
hypothetical clients, or fully immersive experience with a high degree of interaction with community clients or end users. These CELs can look like multi-semester capstone design of a voice controlled wheel chair [20] or to identify and propose a solution for water related sickness in guatamala [21], or first year 1-month long project develop to develop a design to increase quality of life for villagers Jumla, Nepal, or even the development of a local science fair exhibit [22]. These types of CELs are often curricular, usually explicitly framed in a professional context (as opposed to personal), offer a degree of self selection in terms of the nature of different projects available, can vary in degree of relationship with a community partner or human centeredness, range in length from a few weeks (project) to an entire semester or multiple semesters (capstone design project).

Over the last few decades, a few elaborate engineering service-oriented programs have been established: EPICS (Engineering Projects in Community Service) [23] is one of the grandfather programs paving a clear validation and momentum for the practice, there are other programs like SLICE (Service Learning Integrated Throughout a College of Engineering) [24], Global TIES (Teams in Engineering Service) [6]. These programs are often rooted in design context, offer a more established and robust relationship with community partners and similarly flexible opportunities for students to choose projects related to their interests, yet still receive academic credit.

It is clear to see that there is an entire spectrum of programs that could fit within the community engagement pedagogy, as such there are all shapes and sizes that could be leveraged to fill a wide spectrum of graduate attributes.

\subsection{Outcomes of Community Engaged Learning}

Community engaged learning experiences lend themselves to learning objectives through the projectbased, interpersonal and authentic [20] (or 'realistic') learning opportunities.

Astin [14] conducted a substantial longitudinal study of over 22,000 participants to determine the educational benefits of community engaged learning. Astin's main conclusions were regarding the positive relationship between academic, value, self-efficacy, and leadership indicators with service involvement. Other conclusions noted from this large study were that the curricular service opportunities (with instructor fulfilling active role to facilitate the learning) enhanced impact on academic indicators, that the degree of student's interest was the most important factor to positive impact and underscored the importance of student reflection in CEL activities.

Cognitive Learning and Affective Learning

- Academic performance

o Values

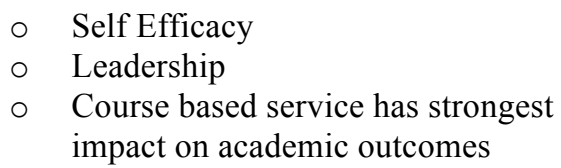

\subsection{Measuring Social Responsibility}

Although there are many possible cognitive and affective benefits from Community Engaged Learning our research is specifically interested in relating this pedagogy to social responsibility development for engineering students and attributes related to the social dimension.

There have been two particular sets of authors that look at measuring engineering-specific development of social responsibility from community engagement learning activities. The first author is Jay Copper [8], who conducted a larger study was a study in early 2000 's, looking at the impact of three types of 'service learning' on social responsibility - the underlying classification of service learning was: curricular, cocurricular and traditional. He used a measurement tool called the "Social Responsibility Index".

The second is a pair of authors, Canney and Bielefeldt, are currently collaboratively and separately creating an expanding body of work on this topic looking at the specific relationship between social responsibility development through community engaged and other course based learning in engineering [8]-[10], [17], [25], [26]. Most notably, they developed a social responsibility framework model that illustrates the manner in which social responsibility may develop (e.g. personally, professionally and in a deeper all-encompassing manner), and then composed a detailed and corresponding survey tool called EPRA (Engineering Professional Responsibility Assessment). The significance from Canney and Bielefeldt's work is that this can be a movement towards systemizing the way in which we measure and report on the success and learning in community engaged learning and other activities impact the social dimension of learning. This step towards systemizing is a welcomed step forward to overcome past characterizations of service learning research as being plagued with limitations including often isolated and anecdotal case studies, an over emphasis on curricularbased learning and lacking a variety of measurable outcomes [11].

\subsection{Slicing and Dicing Community Engaged Learning}


The literature spends time deliberating on the terminology that best fits and has least negative connotations for community engaged learning or service learning, and similarly the classification or categorizing, or scoping of community engaged learning has also been discussed in literature. Some of the terminologies have been discussed in the introduction - but here in the literature review, we focused on ways in which people have used to characterize and classify between the diverse spectrums of community engaged learning. We asked ourselves - how have people tried to classify the vast array of CEL (service learning) experiences, why and for what purpose? We take a broad look at reason for classification, types of differentiation, and finally dive into what common threads can be seen and might be most practical for use in engineering.

Morton's [27] spectrum was proposed in 1995 to elaborate on the term 'service' in the context of service learning. He proposed "three distinct paradigms" of service lies on a linear continuum ranging from "charity, project or social change" [27]. This distinction was made to differentiate the underlying goal for the recipients and motivation of participants. This spectrum was one of the starting places for classifying service learning, but notably does not include any mention of education goals and learning objectives - it specifically refers to service goals. His underlying purpose for this classification is because each type is different; we must focus efforts in one type or another to achieve the underlying goal for each particular type.

In 1994, Sigmond [12] was also developing a typology service learning by using all the possible combinations of primary and secondary objectives and both objectives being equal. For example SERVICE-learning, serviceLEARNING, service-learning or SERVICE LEARNING. This characterization speaks now to the generally agreed upon goals of Community Engaged Learning (CEL), which is balancing the reciprocal nature of meeting learning goals and also community needs. This typology focuses on the overall outcome, or nature for the CEL activity - and was valuable in reinforcing that the reciprocal nature of service learning is a key component to its definition.

In 1996, Furco [12] built off of Sigmond's work to add a second, but parallel, axis regarding the intended beneficiaries for the various combinations of service and learning. Additionally, he contributed to providing a typology and corresponding terminology. In Figure 1, if you select a point on the scale - the corresponding 'type' is titled below it. An interesting feature of this model is the overlap between different 'types'. The types presented here are quite relatable for current studies, and bring momentum to form some meaningful definitions to classify different types of community engaged learning.

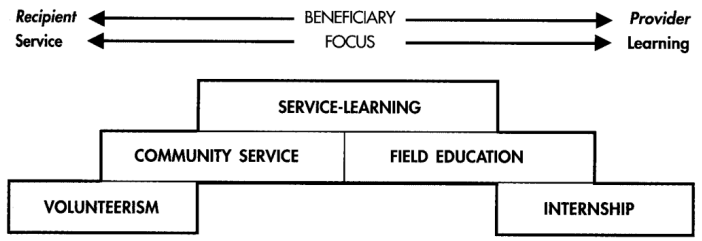

Fig.1 - Furco's [12] two-axis spectrum and four 'types' of service learning.

In 2002, instead of just considering service learning in terms of objectives and beneficiaries, Cooper [11] distinguishes CELs by a one-axis spectrum that uses logistical/context descriptors where increasing academic positioning, is labeled with increasing degree of charitybased to social action. co-curricular vs curricular). His study regarding social responsibly development in engineering students had reported on service learning in three types. The first of these three types is 'Traditional Community Engagement', which is described as more charity based and with little academic structure, and then the other two types are a division between academically oriented experiences, curricular CEL and co-curricular $C E L$. This spectrum imposes that the nature (charity based vs. social action) and academic positioning are set in relation to each other, but excludes other various combinations of academic positioning with social nature of the types. There is also ambiguity in terms of what may be considered "Traditional" CELs.

I would also like to make note that conducting a quick web search, in 2016, of "service learning types" also reveals some interesting trends that universities use to characterize different CELs (see Appendix A for links). Many post secondary institutions, like Northern Illinois, Minnesota Carleton, University of Central Arkinsas, Colorado State among others seem to adapt three to four different types of service learning that are not mentioned above. Most, reference that this classification is based off of a terminology created by the National Service Learning Clearing House (however I could not determine the original document despite the reference to this organization). They distinguish service learning in four ways - indirect, direct, research and advocacy. Some University websites group the advocacy and research types of service learning together, and others have adapted the terminology to call it "Types of Community Engagement" as opposed to "Types of Service Learning". The first two types, direct and indirect refers to whether the project is helping the community in general, in comparison with a project that has direct link and face-toface with community partners receiving the benefits. Research projects refer to collecting and reporting information in the public's interest and advocacy refers to activities around holding public forums, conducting public information campaigns and working with elected officials to create impact for social good. 
In 2013, Vanasupa and Schlemer [15] developed a 2axis, 4-type characterization of CELs (seen in Figure 2). The first axis presents a scale regarding degree a CEL emphasizes learning objectives which echos much of what has been proposed before. The second axis speaks to the nature of the relationship between learners and community partners and distinguishes the difference between "relational" and "transactional" community engaged learning. This is similar to the beneficiary axis presented by Furco, but Furco's model seems to suggest that benefiting the learner or the community is mutually exclusive. This variant considers that learning and societal impact don't have to be mutually exclusive in a trade off manner.

This framework allows a more sophisticated distinction between different kinds of community engaged learning. The two-axis are degree of learning objectives (learning focused) and the type of relationship between the client/community partner and the learner (transactional vs. relational). This developed 4 types of community engaged learning - along with their own term to go with them. This model sets the stage with an increasing distinction between different CELs, and their different resulting consequences on student learning, faculty and the community partners.

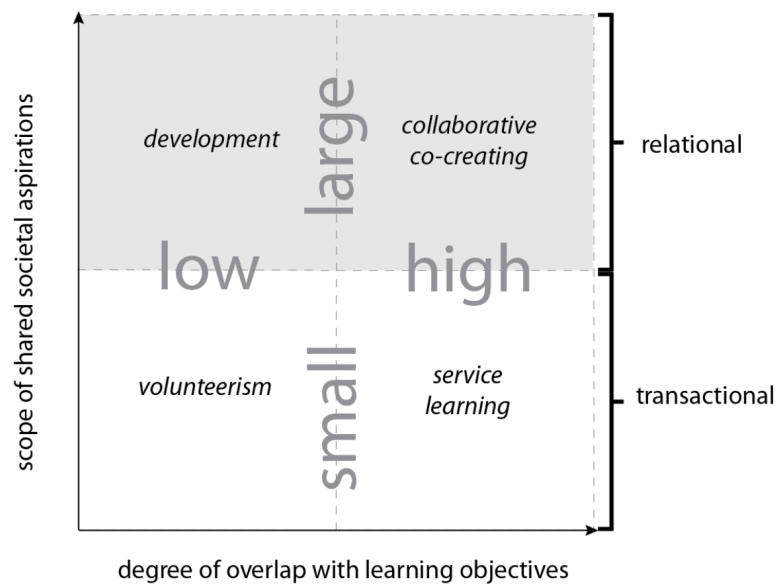

Fig. 2. Vanasupa's et al's [15] two-axis arrangement and four 'types' of Community Engagement

There was also a study conducted by Bielefeldt et al. [28] that used a workshop to take a scan of current ways community engaged learning are occurring. They did this based on a framework that was proposed in the same year that defined different characteristics that could be used to slice, dice or in their words "define, compare and contrast" [28] different types of service learning and cocurricular learning-through-service. A correlation matrix between different characterizing elements from different community engaged learning program was created from the workshops representing many institutions to mark the characteristics of a CEL they have used or use in their programs. The correlation matrix from this study is presented below. Some trends of note are duration and community interaction and social/cultural context are positively related (increase duration, and increase community interaction and social/cultural context), or the correlation between assessments being used if it was based in curricular based service etc. We can start to see some differentiation of exact characteristics, and begin to get a feel for how many variations can really exist in the spectrum of community engaged learning. We can also see a mention of many logistical factors that can have implications on goals and curricular positioning.

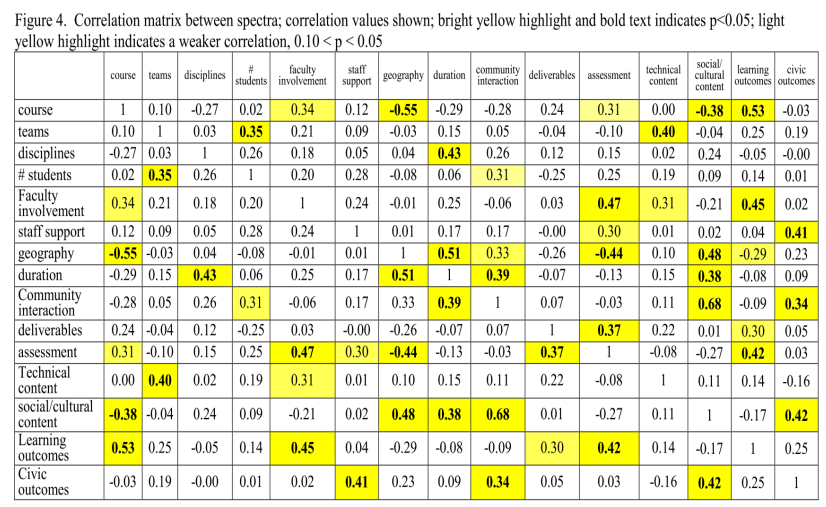

Fig. 3. A correlation matrix of CEL components, Bielefeldt et al. [28]

Lastly, in 2012, McCahan et al. [19] presented an engineering-based 12-dimension model, where each 12 characteristics are categorized in 4 areas: academic, program design, management and technical-social balance. This elaborate model addresses many of the factors we have seen in past typologies and resembles the spectrum of factors represented in Figure 3. They have exhaustively considered all perspectives, including student, institution, and community partner. One element that I would highlight in terms of oriented a CEL towards specifically professional educational outcomes - is a characteristic that considers whether the content of the experience is engineering-specific, engineering-inclusive or non-engineering oriented, and additionally how socially oriented the content is. Despite being much more complex than previous models, this model is most elaborate and well presented.

\section{DISCUSSION}

\subsection{Current labels and models}

The first three examples from Morton, Sigmond and Furco heavily rely on emphasis of a CEL activity in two 
dimensions - service and/or learning and designate the labels them as "volunteerism", "service-learning" or "internship" depending on the ratio of emphasis on service or learning. The service:learning ratio is fundamental to the definition of community engaged learning and it is apparent from these models.

In contrast, in Cooper's study, CEL is distinguished between types of community engagement by giving them a single dimension context-based label through degree of academic emphasis - "cocurricular", "curricular" and "traditional". The assumption in this model is that the context label implies the degree of emphasis on service and/or learning that was more explicit in the other models. The more "curricular" it is on the spectrum - the less emphasis there is on service and more on learning. The fact that there is a "traditional" label implies that community engaged learning was traditionally not considered part of engineering program and anything that is cocurricular or curricular needs it's own distinguishing label. While there is a degree of practicality in that assumption - the mutual exclusivity between service and learning are too closed-off and does not open itself for variations in community engaged learning. We take note however, on the use of more logistical descriptors in contrast with objective-based descriptors as seen previously.

Like the first three models, Vanasupa and Schlemer's model is also two dimensional, but unique to the previous models in that it pairs the learning dimension, with the nature of the service partnership (as either a relationship or transaction). The value in this model is a nuance that is fundamentally critical to successful service partnerships. Service work has been sometimes criticized or perceived as providing short-sighted solutions and being imposing and non-empowering for the beneficiaries of the service offering temporary solutions. This notion is illustrated in the notion of human centered design, co-creation (codesign), and the common mantra to "design with, not for". The emphasis in service is with regard to a cocreation approach that is much more suitable for meaningful, impactful and long-term partnerships that empower the recipients as well as the learners. Overall, this model describes the degree of learning emphasis and type of service relationship in a non-mutually exclusive relationship with labels such "volunteerism", "development", "service learning" and "collaborative cocreating".

The last two references look at community engaged learning by breaking it down into 12-15 elements and attributes that can be used to characterize a type of community engaged learning. There is a large degree of overlap between the two sources - including global vs. local community, curricular positioning, degree of interaction, learning outcomes, civic outcomes etc. This is where we begin to see logistical characteristics combine with theory based elements, which is described by
McCahan et. al's paper as it "sets this model apart from the more theoretical models in the literature."

This format, especially as outlined by McCahan makes testing and describing exact breakdown of community engaged learning ready for reporting and testing which factors may correlate to various outcomes. Such detail can also be used, as Bielefeldt has illustrated through a correlation matrix, to characterize the degree in which we can make assumptions on what is "typical" in for certain "types" of community engaged learning, like the assertions that myself, or Cooper describe when we describe the spectrum of CELs. One thing to note - is instead of describing a CEL with learning emphasis vs. service emphasis, they discuss emphasis on a CEL as having technical emphasis vs. social emphasis.

The breakdown of the 12-15 elements to characterize community engaged learning is valuable, especially for research purposes. However, there is a degree of pragmatism missing to create a typology with 12 dimensions, which is something that the other more theoretical models do allow for. Can we meet somewhere in the middle in a collaborative attempt to combine all the models, in a detailed yet pragmatic format for use of labels that allow for systemized reporting on community engaged learning experiences?

\subsection{The purpose of labels and types of CEL}

To contribute to a meaningful discussion on slicing and dicing the types of community engaged learning, we must first consider what is the purpose of classification of community engaged learning the first place? If I use the terms volunteerism, vs service learning vs collaborative co-creation - so what? As community engaged learning is gaining momentum as a valid and value-added pedagogy in engineering, the number of reports and body of literature on successful community engaged learning is also growing. And as mentioned previously, the field is currently plagued with anecdotal, isolated reports on successes of community engaged learning with no specific measurable outcomes". We would say the main purpose for use of this terminology is for enhancing credibility of this pedagogy and enabling to report on it in a regular and familiar manner. Using similar terminology allows comparisons be made between studies using various types of community engaged learning (apples to apples), and also allows us to vary to measure the "outcomes" of these programs with an agreement of the types and factors of "input" in a systematic way. Secondly a common set of terminology would contribute to facilitation translation from research to practice.

The ultimate goal, ideally, if we were to find an ideal version to categorize "types" of CEL, those reviewing research on CEL or choosing types of CEL experiences should (at least) be able to: 
1. Search and select for suitable CEL types for given logistical context

2. Situate various examples of CELs within clear categories based on an intuitive set of CEL characteristics

3. Distinguish particular features of a particular type of CEL

4. Associate particular types of CEL with particular learning outcomes (pending future research to strengthen the link between CEL type and outcomes) - such as social responsibility or particular attributes.

5. Test and report on outcomes and relations of CEL type and features.

Next we must look at what are the important factors and attributes to community engaged learning. Given most definitions it is fair to assume that the threshold for community engagement: Learning must happen, community engagement (service) must happen and reflection must happen. We can see the goal being service or learning is key in distinguishing one from the other. We can also see the introduction of logistical descriptors to situate types of community engagement in academic context can be valuable from a practical sense on converting theory to practice. (e.g. cocurricular, curricular).

At the end of the day, community engagement is a pedagogy, which is composed out of an academic context with outcomes for two main stakeholders - the students and the community. Thus the components to consider are logistics and positioning, learning objectives, learning activities, learning assessment and similarly - community partner objectives, community partner deliverables, and measures of meeting community needs.

By looking at this - we can consider firstly that logistical descriptor in specifying a "type" of community engagement are important towards implementation. Those aiming to find suitable implementation types for their own context will be consulting literature to find out about particular "types" of community engaged learning through this filter first, as it has most implications towards structure and resources. (e.g. curricular, co-curricular, etc.)

Secondly, we can move forward through use of a descriptor that distinguishes the goal of the learning, like the degree of learning, and type of service relationship to the community partner. Something like Vanasupa and Schelemer's labels could be used to supplement logistical descriptor - such as volunteerism, service learning, development(al), and collaborative co-creation. This set of labels is more meaningful than variations or servicelearning provided by Sigmond which all sound similar, and Furco's labels that include "field experience" and "internship" which are arguably out of the scope of community engaged learning. In addition to the four labels here - perhaps a one additional label can be added for more technical or traditionally oriented experiences.

Lastly, as community engagement is pedagogy, it should be complete with learning objectives, learning activities and assessment among other features. It is expected that most of the reporting will feature measures on various learning outcomes, through manipulating various learning activities (e.g. reflection, intrinsic vs. extrinsic motivation) or other features. This will be the more intriguing part of the studies to see what various features of a community engaged learning experience can be leveraged for particular outcomes. Additionally, these are where the features for comparison, trends for implementation, and for new findings can be highlighted.

Thus three levels of descriptors can be considered the first is with regard to logistical descriptor, the second orients the learning and service goal, and lastly are the highlighted features in that community engagement type.

\subsection{The Thought experiment using three levels of descriptors}

To try out this conceptual labeling structure for CELs, I draw on the syntax of English language formation.

Starting with a noun - let's look at a "bag" and how we can modify that word to include a more meaningful description. Typically attributes (adjectives) go before the main noun - a blue bag. If there is an adjective that describes the purpose of the object it is included after other various attributes - such as a big, blue school bag. Lastly the features of that object can be supplemented after the noun (a relative clause) to give more information to the noun - a big, blue school bag with polka dots.

Similarly, in this thought experiment we can describe community engaged learning experiences to include the three levels mentioned above - logistical descriptors (adjective), goal descriptor (purpose adjective), what it is (noun, eg. A course) and highlighted features of that community engaged learning (relative clause).

(logistics $)+($ goal/type $)+[$ what it is $]+$ highlighted features

This formation can be used to describe a community engaged learning type verbally, or group them, but can certainly be supplement with the specific 12-15 factors in detail for more elaborate research comparisons.

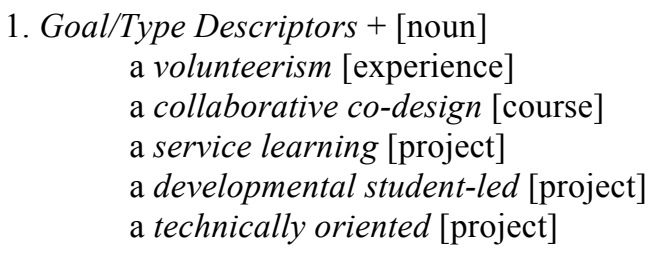




\section{Logistical descriptors $+($ goal/type $)+[$ noun $]$}

a capstone design technical course a first year design service learning course a spring break abroad volunteer experience a technology and society traditional course a curricular service learning program a student-led global collaborative co-design program

\section{Logistical descriptors $+($ goal/type $)+[$ noun $]+$} features and highlights

a first year design service learning course with a focus on user empathy

a capstone design technical course infused with some community-engaged projects

a short-term abroad volunteer experience highlighting social responsibility measures a technology and society traditional course featuring reflective short essays a curricular service learning program rooted in CDIO framework a student-led global collaborative co-design program

\section{CONCLUSIONS}

The practice of community engaged learning is gaining momentum in engineering, and due to the newness is still a little rough around the edges in the research community with regard to consistent reporting and use of terminology.

Upon review of a variety of models for breaking down community engaged learning, we see two ways to discuss types of CEL. The first type are more theory-based and simple types that can refer to the variation of goal between service and learning, and secondly an elaborate 12-15 element way to breakdown a community engagement learning activity that includes both goal, and logistical elements to characterize community engaged learning.

The theoretical ones are valuable as quick reference but missing elements paint more of a picture in relation to engineering context and positioning, and the multidimensional ones are less practical for reporting on research or making reference to a "type" unless for creating a database, or for doing detailed factor analysis.

To add to the conversation, but in a collaborative attempt to work with the models that exist - we have done a review and thought experiment towards something that can role off the tongue (or the typing fingers) yet still speak to a degree of logistical elements, "type" and features - such as in the form (logistic descriptors) + (goal/ "type") + [what it is] + highlighted features.
The overall goal is not to impose a new format for describing community engaged learning, but ultimately to evoke discussion and consensus towards the characteristics that can be used to slice and dice community engaged learning. Through this literature review, and thought experiment - we can certainly see that there is an entire spectrum of elements that can be used to describe a community engaged learning experience.

Ultimately, keeping in mind the elements that compose a community engaged learning experience we can consider how we discuss, compare and contrast one study on community engaged learning from the next. The current models and 'types' are more theoretical, and so further explorations could include review similar to correlation matrix similar to what is seen in the paper to concretely differentiate and categorize based on how community engaged learning is actually implemented.

\subsection{Future Work}

The authors' are currently researching how various types of community engaged learning impact social responsibility development. The future analysis will use this format to group the types of community engaged learning experiences and relate them to development of various social responsibility outcomes and graduate attributes. Findings will need to be compared to other various studies in literature, and as such, it was necessary to consider the methods to categorize community engaged learning experiences that consider factors that could relate to the outcomes.

\section{Acknowledgements}

The authors wish to thank the Suncor Energy Foundation for their generous support of this research.

References

"NAE Grand Challenges for Engineering," Committee of the National Academy of Engineering, 2008. [Online]. Available: http://www.engineeringchallenges.org/cms/challe nges.aspx. [Accessed: 15-Feb-2015].

[2] E. Conlon, "The new engineer: between employability and social responsibility," Eur. J. Eng. Educ., vol. 33, no. 2, pp. 151-159, 2008.

[3] ABET, "2014-2015 Policies and Procedures Manual," Engineering Accreditation Commission, 2015. [Online]. Available:

http://www.abet.org/accreditation-criteriapolicies-documents/. [Accessed: 30-Apr-2015]. CEAB, "2014 Accreditation Criteria and Procedures," Engineers Canada, 2014. [Online]. Available:

http://www.engineerscanada.ca/sites/default/files/ 
2014_accreditation_criteria_and_procedures_v06. pdf. [Accessed: 30-Apr-2015].

[5] H. Zandvoort, "Preparing engineers for social responsibility," Eur. J. Eng. Educ., vol. 33, no. 2, pp. 133-140, 2008.

[6] M. Bratton, "Global TIES : Ten Years of Engineering for Humanity," no. 2009, pp. 205221, 2014.

[7] A. D. C. Chan and J. Fishbein, "A global engineer for the global community," J. Policy Engagem., vol. 1, no. 2, 2009.

[8] N. E. Canney, "ASSESSING ENGINEERING STUDENTS' UNDERSTANDING OF PERSONAL AND PROFESSIONAL SOCIAL RESPONSIBILITY," 2013.

[9] N. E. Canney and A. R. Bielefeldt, "Differences in Engineering Students 'Views of Social Responsibility between Disciplines," J. Prof. Issues Eng. Educ. Pract., vol. 04015004, no. 10, pp. 1-10, 2015.

[10] A. Bielefeldt, "Social Responsibility Attitudes of First Year Engineering Students and the Impact of Courses Social Responsibility Attitudes of First Year Engineering Students and the Impact of Courses," ASEE Annu. Conf. Expo. Conf. Proc., 2014.

[11] J. R. Cooper, "Social Responsibility and Types of Service Learning," Western Michigan University, 2002.

[12] A. Furco, "Service-learning: A balanced approach to experiential education," Expand. Boundaries Serv. Learn., vol. 1, pp. 1-6, 1996.

[13] W. Oakes, "Creating-Effective-and-EfficientLearning-Experiences-While-Addressing-theNeeds-of-the-Poor-an-Overview-of-ServiceLearning-in-Engineering-Education," 2009.

[14] A. W. Astin, L. J. Vogelgesang, E. K. Ikeda, and J. a Yee, "How Service Learning Affects Students," High. Educ., vol. 14, pp. i-104, 2000.

[15] L. Vanasupa and L. Schlemer, "Relational versus transactional community engagement: An experience of the benefits and costs," in American Society for Engineering Education, 2014.

[16] A. R. Carberry, "Characterizing learning-throughservice students in engineering by gender and academic year.," Diss. Abstr. Int. Sect. A Humanit. Soc. Sci., no. August, p. 2021, 2010.

[17] N. E. Canney and A. R. Bielefeldt, "Engineering Students ' Views of the Role of Engineering in Society," 2012.

[18] L. Jatana Vathje, M. Eggermont, and R. Brennan, "Homes of Hope: Visualizing Social Responsibiity," in Canadian Engineering Education Association Conference, 2015, no. April, pp. 1-10.
[19] S. McCahan, H. K. Ault, E. Tsang, M. P. Henderson, S. P. Magleby, and A. Soisson, “A Multi-Dimensional Model for the Representation of Learning Through Service Activities in Engineering," Am. Soc. Eng. Educ., no. June, 2012.

[20] M. Jawaharlal, U.-J. Fan, and S. Monemi, "Implementing Service Learning in Engineering Curriculum," 2006.

[21] D. P. Michelfelder and S. A. Jones, "FROM CARING ABOUT SUSTAINABILITY TO DEVELOPING CARE-FUL ENGINEERS," EESD'15 Conf. Eng. Educ. Sustain. Dev., pp. 1-8, 2015.

[22] R. Shelby, F. Ansari, E. Patten, L. Pruitt, G. Walker, and J. Wang, "Implementation of leadership and service learning in a first-year engineering course enhances professional skills," Knowl. Soc. Sel. Pap. Eng. Educ. from 4th World Summit Knowl. Soc., vol. 29, no. 1, pp. 85-98, 2013.

[23] W. Oakes and J. Spencer, "EPICS: engineering projects in community service," 34th Annu. Front. Educ. 2004. FIE 2004., vol. 21, no. 1, 2004.

[24] J. Duffy, L. Barrington, C. West, M. Heredia, and C. Barry, "Service-learning integrated throughout a college of engineering (SLICE)," Adv. Eng. Educ., vol. 2, pp. 1-23, 2010.

[25] A. R. Bielefeldt, K. G. Paterson, and C. W. Swan, "PROJECT-BASED SERVICE LEARNING," pp. 1-14.

[26] a. R. Bielefeldt, "Global Interests among FirstYear Civil and Environmental Engineering Students," J. Prof. Issues Eng. Educ. Pract., vol. (in press), pp. 1-9, 2013.

[27] K. Morton, "Morton, Keith. 1995. 'The Irony of Service: Charity, Project, and Social Change in Service- Learning.' Michigan Journal of Community Service Learning2 : 19-32.," Michigan J. Community Serv. Learn., no. 2, pp. 19-32, 1995.

[28] A. R. Bielefeldt, K. G. Paterson, O. Pierrakos, C. Swan, and david o Kazmer, "Spectra of Learning Through Service Programs,” 2013.

\section{APPENDIX A: Web Search Results for "Types of Service Learning"}

1. Northern Illinois

http://facdevblog.niu.edu/service-learning

2. Minnesota

http://www.servicelearning.umn.edu/cesp/programdetails/engagement t ypes.html

3. Carelton https://serc.carleton.edu/econ/service/project type.html

4. University of Central Arkansa https://uca.edu/servicelearning/types/

5. Colorado State http://tilt.colostate.edu/service/about/typesOfSL.cfm 